\title{
Concentrações sangüíneas de metais pesados e praguicidas organoclorados em crianças de 1 a 10 anos
}

\section{Heavy metal and organochlorine pesticide blood levels in children aged between 1 and 10}

Eladio Santos Filho*, Rebeca de Souza e Silva"*, Heloisa H. C. Barretto**", Odete N. K. Inomata***, Vera R. R. Lemes"**, Alice M. Sakuma***, Maria Anita Scorsafava***

\begin{abstract}
SANTOS FILHO, E. et al. Concentrações sangüíneas de metais pesados e praguicidas organoclorados em crianças de 1 a 10 anos. Rev. Saúde Pública, 27:59-67, 1993. Foi realizado estudo em 6 bairros do Município de Cubatão, SP, Brasil, situados às margens dos principais rios do município, com uma amostragem de 251 crianças de 1 a 10 anos de idade. Foram verificadas as concentrações sangüíneas de praguicidas organoclorados em 242 crianças, sendo que 73 crianças (30\%) apresentaram concentrações de p-p'DDE ( $\vec{x}=0,85 \pm 2,13 \mu \mathrm{g} / \mathrm{l}$ ), e em 47 crianças (19\%) foi encontrado $\mathrm{HCH}$ total $(\overline{\mathrm{x}}=0,28 \pm 0,79 \mu \mathrm{g} / \mathrm{l}$.). Verificou-se também a concentração sanguiínea de chumbo e mercúrio, sendo que se obteve a plumbemia média de $17,8 \pm 5,8 \mu \mathrm{g} / \mathrm{dl}$. e concentração média de mercúrio de $9,1 \pm 6,4 \mu \mathrm{g} / \mathrm{l}$. Crianças consumidoras de organismos aquáticos de origem exclusiva dos rios de Cubatão apresentaram teores médios de mercúrio ( $\overline{\mathrm{x}}=14,7 \pm 7,1 \mu \mathrm{g} / \mathrm{l}$ ) significativamente maiores $(p<0,04)$ em comparação às crianças não consumidoras de organismos aquáticos de qualquer origem $(\overline{\mathrm{x}}=10,0 \pm 6,5 \mu \mathrm{g} / 1$.).
\end{abstract}

Descritores: Inseticidas organoclorados, sangue. Chumbo, sangue. Mercúrio, sangue. Peixes.

\section{Introdução}

Uma das razões determinantes à decisão de se implantar o maior pólo sidero-petroquímico da América Latina no Município de Cubatão, foi a relativa abundância de água de boa qualidade proveniente das bacias hidrográficas do rio Cubatão e seus afluentes. Esses rios nascem na Serra do Mar em região de florestas e "cortam" a zona industrial do município recebendo toda a descarga de esgotos domésticos e industriais. Recebem também as descargas dos canais 1 e 2 da Usina Hidroelétrica Henry Borden, com águas procedentes do sistema Alto Tietê, através do reservatório Billingss que constitui o corpo receptor de grande parte dos dejetos domésticos e industriais da Grande São Paulo.

Orio Cubatãoé um importante manancial utiliza-

\footnotetext{
* Secretaria de Estado da Saúde de Cubatão - São Paulo (Brasil).

** Faculdade de Saúde Pública da Universidade de São Paulo - São Paulo (Brasil).

*** Instituto Adolfo Lutz - São Paulo (Brasil).
}

Separatas/Reprints: E. Santos Filho - Rua Praia dos Sonhos, 79 - Vila Guilhermina - 11701-390-Praja Grande, SP - Brasil.

Edição subvencionada pela FAPESP. Processo Medicina 93/ 0208-5. do pela Companhia de Saneamento Básico do Estado de São Paulo (SABESP) para o abastecimento público de 5 municípios da região, fornecendo água tratada a, aproximadamente, um milhão de habitantes. A Companhia de Tecnologia de Saneamento Ambiental (CETESB) procede, através de 5 estaçōes de coleta, ao monitoramento de alguns parâmetros fisico-químicos das águas do rio Cubatão 5 . De acordo com dados publicados pela CETESB ${ }^{6}$, até julho de 1984 eram despejados no rio Cubatão 64 toneladas/dia de poluentes, sendo que devido ao programa de controle ambiental, implantado a partir desse ano, verificou-se redução total de $93,8 \%$ desses poluentes assim distribuída: $93 \%$ de redução de $\mathrm{DBO}, 90 \%$ de carga de resíduos sólidos, $97 \%$ dos metais pesados, $80 \%$ dos fenóis e $96 \%$ dos fluoretos.

Um dos reflexos da redução dessa carga poluidora foi o reaparecimento dos peixes a partir de 1988. Desde então, esses peixes e outros organismos dos rios de Cubatão vêm sendo consumidos pela população. Estudos de contaminação da biota aquática dos rios de Cubatão, realizados pela CETESB ${ }^{5}$, demonstraram que os peixes desses rios estão impróprios ao consumo humano devido aos altos teores de contaminantes apresentados, a saber: $50 \%$ das amostras de musculatura (parte comestível) apresentaram teores de chumbo acima dos limites permissiveis de $0,5 \mu \mathrm{g} / \mathrm{g}^{5}$ e $5,6 \%$ das amostras ultrapassaram os limites permissíveis de 
$0,5 \mu \mathrm{g} / \mathrm{g}$ para o mercúrio ${ }^{5}$ A maior concentração de mercúrio encontrada em musculatura de peixes pesquisados foi de $0,9 \mu \mathrm{g} / \mathrm{g}$. Foram detectadas também hexaclorociclohexano $(\mathrm{HCH})$ e hexaclorobenzeno (HCB) em $46 \%$ e $74,7 \%$ das amostras de musculatura analisadas, respectivamente. A maior concentração de $\mathrm{HCH}$ encontrada foi de $0,05 \mu \mathrm{g} / \mathrm{g}$ e de $\mathrm{HCB}$ foi de $0,02 \mu \mathrm{g} / \mathrm{g}$, valores abaixo dos limites permissíveis de $0,2 \mu \mathrm{g} / \mathrm{g}^{5}$. Em função desses achados, foi realizada a presente pesquisa, em crianças de 1 a 10 anos de idade residentes às margens dos rios de Cubatão, com o objetivo de conhecer nessa população as concentraçðes sangüíneas de chumbo, mercúrio e de praguicidas organoclorados, a saber: Hexaclorociclohexano ( $\mathrm{HCH}$ total, somatória de alfa $\mathrm{HCH}$, beta $\mathrm{HCH}$ e gama $\mathrm{HCH}$ ), Heptaclor, Heptaclorepoxi, Dieldrin, Endrin, DDT (isômeros o-p'DDT e p-p'DDT e metabólitos p-p'DDD e p-p'DDE), Mirex e Hexaclorobenzeno (HCB).

\section{Material e Método}

\section{Delineamento do estudo}

Para eliminar as variáveis de confusão como o tabagismo e a exposição ocupacional, decidiu-se trabalhar com crianças de 1 a 10 anos de idade. Para a determinação dos teores sangúíneos dos xenobióticos estudados, foi realizado um "survey" do tipo transversal. Para estabelecer relação entre os teores sanguíneos das substâncias pesquisadas e o consumo de peixes e/ou produtos dos rios de $\mathrm{Cu}$ batão, foram formados dois grupos constituídos por crianças grandes consumidoras e crianças nãoconsumidoras. Foram consideradas grandes consumidoras as crianças com referência de consumo de peixes e/ou outros produtos dos rios de Cubatão com a freqüência maior ou igual a uma vez por semana $e$ por um período nunca inferior a 6 meses. Como nãoconsumidoras foram consideradas as crianças com referência negativa de consumo de peixes e/ou outros produtos aquáticos de qualquer origem.

\section{Local do estudo}

A presente pesquisa foi realizada em 6 bairros do Município de Cubatão (Fig.), escohidos por apresentarem característica comum de se localizarem às margens dos rios e com facilidade de acesso a eles.

As características dos bairros pesquisadas, são as seguintes:

a) Jardim Costa e Silva: bairro central do $\mathrm{Mu}$ nicípio de Cubatão, com população de 2.759

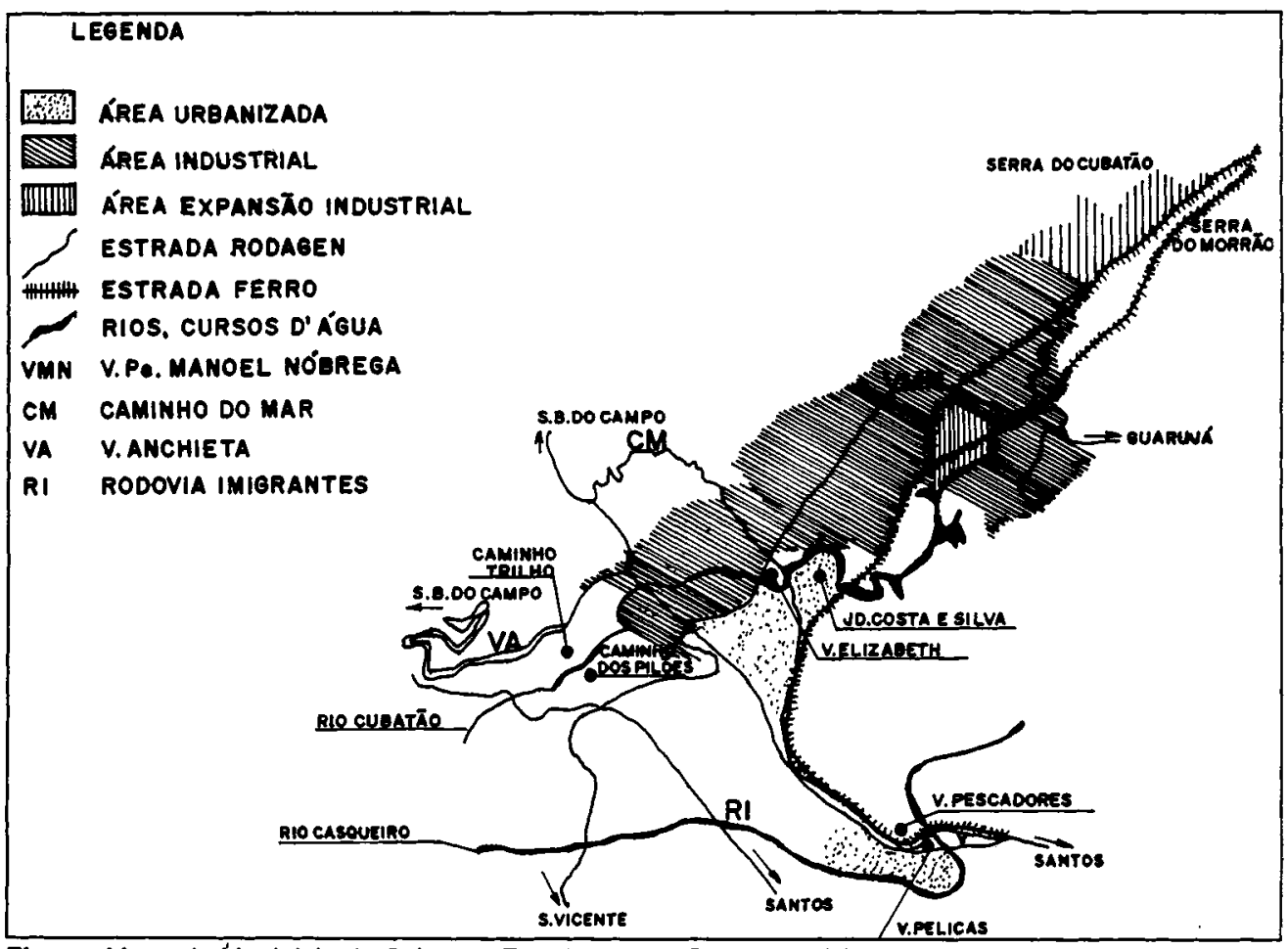

Figura. Mapa do Município de Cubatão, Estado de São Paulo (S/ESC.). 
habitantes*. É residencial típico de classe média com infra-estrutura urbana completa. Possui tráfego de veículos pouco intenso e localiza-se, aproximadamente, a $3 \mathrm{~km}$ (por terra) das indústrias mais próximas (petroquímicas).

b)Vila Elizabeth: bairro central do município, de classe média baixa e pobre, com 783 habitantes*, possuindo abastecimento de água tratada mas sem rede coletora de esgotos. Situase às margens de rodovia estadual (rodovia Pedro Taques) com intenso tráfego de veículos e a 500 metros de indústria petroquímica e de refino de petróleo.

c) Vila dos Pescadores: trata-se de favela situada parte em terreno seco e parte sobre mangue, com barracos interligados por frágeis passarelas erguidas com restos de material de construção. Seus 4.283 habitantes* vivem precariamente, sem qualquer infra-estrutura urbanosanitária. Localiza-se às margens de rodovia estadual de tráfego intenso de veículos (rodovia Anchieta) e dista, aproximadamente, $6 \mathrm{~km}$ (por terra) das indústrias mais próximas (petroquímicas e de papel).

d)Pelicas: bairro de classe média baixa com 91 habitantes* pertencentes a uma mesma família. Localiza-se ao lado do bairro Vila dos Pescadores, separados apenas por uma linha férrea. Não possui rede coletora de esgotos, mas recebe água tratada.

e) Caminho dos Trilhos: bairro localizado na periferia do município de classe pobre e sem infra-estrutura urbano-sanitária. Situa-se à margem esquerda do rio Cubatão e possui 457 habitantes*. Apresenta nas imediaçőes uma indústria de papel e papelão e dista, aproximadamente, $3 \mathrm{~km}$ das indústrias mais próximas (petroquímicas). As residências são servidas por água de bicas da Serra do Mar através de ligaçōes feitas pelos próprios moradores. Suas vias não são pavimentadas e apresentam reduzido tráfego de veículos.

f) Caminho dos Pilðes: bairro situado à margem direita do rio Cubatão apresentando condiçð̋es semelhantes ao bairro Caminho dos Trilhos, na margem oposta, à exceção da principal via de acesso ao bairro que é pavimentada. Possui população de 256 habitantes*.

\section{Instrumento de medida}

Para a determinação da freqüência de consumo dos produtos dos rios, elaborou-se um formulário

(*) Prefeitura Municipal de Cubatão: estimativa para 0 ano de 1989. Informação pessoal. de inquérito alimentar, utilizando-se o método recordatório dos últimos 6 meses da data de aplicação do formulário. Acreditou-se que este período de tempo não tenha prejudicado a memória dos entrevistados devido a alta especificidade do alimento pesquisado. A aferição do instrumento de medida foi feita através de pré-teste em 57 familias residentes nos bairros pesquisados mas não pertencentes à amostra. A aplicação do formulário foi feita por duas estudantes de nível secundário especialmente treinadas.

\section{Seleção da amostra}

Adotou-se o critério da acessibilidade para a determinação das unidades amostrais e este critério diferiu de bairro para bairro. No Jardim Costa e Silva foram sorteadas 10 ruas do bairro e todas as residências situadas nas ruas sorteadas foram visitadas pelos pesquisadores, aproximadamente, $40 \%$ do total de residências existentes no bairro. Nos bairros Vila Elizabeth e Pelicas, visitou-se $100 \%$ das residências existentes. Nos bairros Caminho dos Trilhos e Caminho dos Piloes, fizeram parte da pesquisa as residências situadas nos principais núcleos, o que constituiu cerca de $70 \%$ do total de moradias existentes. No bairro Vila dos Pescadores, pela dificuldade de acesso, escolhemos as residências localizadas em terreno seco, o que representou, aproximadamente, $25 \%$ do total de moradias existentes. Esclarece-se que não intencionou-se obter amostras representativas de cada bairro.

Ao todo foram visitadas 773 residências, sendo que 155 foram consideradas fechadas após duas tentativas em dias diferentes e em 7 houve recusa à entrevista. Restaram, assim, 611 residências em que foram aplicados os formulários, num total de 620 famílias entrevistadas. Nessas 620 famílias encontraram-se 696 crianças de 1 a 10 anos de idade. Excluídas as crianças que não se enquadraram como grandes consumidoras ou não-consumidoras, restaram 346 crianças que foram convidadas através de visita domiciliar a comparecer em local e data pré-determinados, para coleta de material para exames laboratoriais. Responderam ao convite 281 crianças $(81,2 \%)$. Durante a coleta de material, reformularam-se as questōes do inquérito alimentar e, assim, excluíram-se da amostra 30 crianças que não confirmaram informaçð̃es anteriores sobre consumo de peixes e/ou outros produtos aquáticos. $O$ universo da pesquisa constituiu-se, então, de 251 crianças, divididas em 53 crianças grandes consumidoras de peixes e/ou outros organismos dos rios de Cubatão mas também de outras origens $(++), 18$ crianças grandes consumidoras de organismos aquáticos exclusivamente dos rios de $\mathrm{Cu}$ batão (+-), 148 crianças grandes consumidoras de 
peixes e/ou outros produtos de diversas origens que não os rios de Cubatão $(-+)$ e 32 crianças não consumidoras de organismos aquáticos de qualquer origem (- -). Para estudar a relação entre concentração orgânica dos xenobióticos e consumo de peixes, foram utilizados os dados apenas das crianças classificadas com (+ -) e (- -).

\section{Coleta de material}

A equipe de coleta de material foi composta por um médico pediatra, uma enfermeira de nível universitário e duas auxiliares de enfermagem. As crianças compareceram nos postos de coleta, localizados invariavelmente nos postos de saúde ou escolas dos bairros, acompanhadas dos pais ou responsáveis. Foram submetidas a um exame físico e a um breve interrogatório sobre o uso de medicamentos tópicos ou sistêmicos e questōes do inquérito alimentar. Após tais procedimentos, colheu-se $20 \mathrm{ml}$. de sangue em veia periférica. Ao final de cada jomada de trabalho, todo material era imediatamente entregue ao laboratório responsável pela execução das análises.

\section{Metodologia laboratorial}

As amostras de sangue coletadas foram encaminhadas ao Instituto Adolfo Lutz/Regional de Santos, onde o soro foi separado e enviado ao laboratório central de São Paulo. O método empregado nas determinaçбes dos praguicidas organoclorados foi o de Dale \& Milles ${ }^{9}$ com modificações conforme descrito no trabalho de Lara e col. ${ }^{17}$. O limite de determinação do método foi de $0,5 \mu \mathrm{g} / 1$ para $\mathrm{HCB}$, $\mathrm{HCH}$ e de 1,0 $\mu \mathrm{g} / \mathrm{l}$ para p-p' DDE, o-p' DDT e p-p' DDT. As determinaçð̃es do chumbo e do mercúrio foram feitas por espectrofotometria de absorção atômica. A metodologia empregada nas determinaçōes do chumbo está descrita nos trabalhos de Subramanian e Meranger ${ }^{24}$ e Subramanian ${ }^{25}$ e no trabalho de Fernandez e Hillgoss ${ }^{11}$. A metodologia empregada nas determinações do mercúrio está descrita no manual Perkin-Elmer Corporation ${ }^{20}$. Para efeito de cálculo estatístico, considerou-se 0 valor zero para as concentrações inferiores ao limite de determinação do método empregado.

\section{Resultados e Discussão}

Das 251 crianças da amostra, foi possível determinar os teores sangüíneos dos praguicidas organoclorados em 242 (96,4\%). Dentre as substâncias pesquisadas, encontrou-se a presença de DDT e de metabolitos, $\mathrm{HCH}$ e $\mathrm{HCB}$. O DDT foi encontrado em 5 crianças $(2,07 \%)$ com teores que variaram de 1,3 a $5,1 \mu \mathrm{g} / 1$. A concentração média de DDT no sangue das 242 crianças analisadas foi de $0,06 \pm$ $0,44 \mu \mathrm{g} / \mathrm{l}$. O metabolito $\mathrm{p}-\mathrm{p}^{\prime} \mathrm{DDE}$ foi encontrado em 73 crianças $(30,17 \%)$. As concentraçōes variaram de 1,0 a 19,6 $\mu \mathrm{g} /$. A concentração média do total de crianças analisadas foi $0,85 \pm 2,13 \mu \mathrm{g} / \mathrm{l}$. $\mathrm{O}$ alfa $\mathrm{HCH}$ foi encontrado em 4 crianças $(1,65 \%)$. Os teores variaram de 0,5 a $1,3 \mu \mathrm{g} / \mathrm{l}$. O teor médio das 242 crianças analisadas foi de $0,01 \pm 0,1 \mu \mathrm{g} / \mathrm{l}$. $\mathrm{O}$ beta $\mathrm{HCH}$ foi detectado em 34 crianças $(14,05 \%)$. Apresentou concentraçōes entre 1,0 a $4,7 \mu \mathrm{g} / \mathrm{l}$. $\mathrm{O}$ teor médio foi de $0,22 \pm 0,63 \mu \mathrm{g} / \mathrm{l}$. $\mathrm{O}$ gama $\mathrm{HCH}$ (Lindano) foi encontrado em 9 crianças $(3,72 \%)$. Os teores variaram de 0,5 a $36,0 \mu \mathrm{g} / \mathrm{l}$. A concentração sanguíínea média entre o total de crianças analisadas foi de $0,42 \pm 2,79 \mu \mathrm{g} /$. Verificou-se, ainda, duas crianças $(0,83 \%)$ que apresentaram concentrações de 0,5 e $0,8 \mu \mathrm{g} /$. de $\mathrm{HCB}$ no sangue.

A Tabela 1 mostra as concentrações sanguiíneas médias de p-p'DDE por sexo e faixa etária. Observou-se que os teores médios de p-p'DDE foram significativamente maiores $(p<0,05)$ na faixa etária de 5 a 10 anos (3,1 vezes maior no sexo feminino e 2,0 vezes maior no sexo masculino). No entanto, não houve diferença estatística dos teores sangüíneos entre os sexos, considerando-se a mesma faixa etária.

Tabela 1. Concentrações sangüineas médias de p-p'DDE por sexo $\theta$ faixa etária em crianças residentes no Municipio de Cubatão, SP.

\begin{tabular}{|c|c|c|c|c|c|c|c|}
\hline \multirow{2}{*}{$\begin{array}{c}\begin{array}{c}\text { Faixa } \\
\text { Etária }\end{array} \\
1 \vdash 5 \text { Fom. }\end{array}$} & \multirow{2}{*}{$\frac{N}{47}$} & \multicolumn{3}{|c|}{$\begin{array}{l}\text { Var. Individuais } \\
\mu \mathrm{g} / \text {. }\end{array}$} & \multicolumn{3}{|c|}{$\begin{array}{c}\text { Média } \pm D P \\
\mu g \wedge .\end{array}$} \\
\hline & & 0 & $\langle->$ & 6,9 & 0,36 & \pm & 1,14 \\
\hline Masc. & 45 & 0 & $<->$ & 6,2 & 0,53 & \pm & 1,18 \\
\hline \multirow{2}{*}{$5 \vdash 11_{\text {Masc. }}^{\text {Fem. }}}$. & 81 & 0 & $\longleftrightarrow->$ & 19,6 & 1,13 & \pm & 2,65 \\
\hline & 69 & 0 & $<->$ & 15,5 & 1,05 & \pm & 2,37 \\
\hline Total & 242 & 0 & $\longleftrightarrow \longrightarrow$ & 19,6 & 0,85 & \pm & 2,13 \\
\hline
\end{tabular}


Radomski e col. ${ }^{21}$ pesquisando crianças argentinas, também observaram concentrações médias de p-p'DDE mais elevadas em crianças de 5 a 10 anos de idade $(\bar{x}=8,13 \pm 4,06 \mu \mathrm{g} /$.) em comparação às da faixa etária de 1 a 5 anos ( $\bar{x}=5,56 \pm 4,83 \mu \mathrm{g} / 1$.).

A Tabela 2 mostra as concentrações médias de p-p'DDE por local de residência. As crianças residentes no bairro Jardim Costa e Silva apresentaram o maior teor médio desse praguicida, sendo que $45 \%$ do total de crianças pesquisadas nesse bairro apresentaram concentraçōes sangüíneas detectáveis de p-p'DDE.

Almeidal verificou em adultos residentes no Rio de Janeiro a concentração média de p-p'DDE de $155 \pm 32 \mu \mathrm{g} / \mathrm{l}$. e em residentes no Espírito Santo o teor médio de $117 \pm 36 \mu \mathrm{g} /$.

Costa $^{8}$ encontrou em 28 pré-escolares matriculados em creches municipais da cidade de São Paulo a concentração sangüínea média de $7,68 \mu \mathrm{g} /$. de p-p'DDE.

Pesquisa publicada pela Organização Panamericana de Saúde ${ }^{19}$ realizada em crianças residentes em 4 estados norte-americanos, revelou a concentração média de $8,37 \mu \mathrm{g} / 1$. de p-p'DDE.

Quase todas as comunicações sobre a concentração de DDT total no sangue de indivíduos de distintos países assinalam cifras que variam de 10 a $70 \mu \mathrm{g} /{ }^{19}$. Em função disso e comparando-se com os resultados descritos acima, os teores médios de p-p'DDE encontrados na presente pesquisa não demonstram exposição recente ao DDT nas crianças pesquisadas.

$\mathrm{Na}$ Tabela 3 são apresentadas as concentrações sangüíneas médias por situação de consumo de peixes e/ou outros organismos dos rios de $\mathrm{Cu}$ batão. Utilizando-se o teste de hipóteses para as médias de duas populaçðes não correlatas, verifica-se que, a um nível de significância igual a 5\%, as taxas sangüineas médias de p-p'DDE não diferem estatisticamente entre consumidores e nãoconsumidores.

A Tabela 4 mostra as concentrações médias de $\mathrm{HCH}$ total no sangue por sexo e faixa etária. Não foi encontrada diferença estatística entre os teores médios de $\mathrm{HCH}$ total no sangue em relação a essas variáveis

Radomsky e col. ${ }^{21}$ encontraram em 37 crianças argentinas de 1 a 10 anos a concentração média de $7,04 \mu \mathrm{g} / \mathrm{l}$. de $\mathrm{HCH}$ total. O gama HCH (Lindano) foi encontrado na concentração média de $0,32 \pm$ $0,24 \mu \mathrm{g} /$. em crianças de 1 a 5 anos e no teor médio de $0,43 \pm 0,34 \mu \mathrm{g} / \mathrm{l}$. em crianças de 5 a 10 anos de idade. Em função dos baixos teores sangüíneos encontrados nas crianças pesquisadas em Cubatão, afigura-se a inexistência de fontes recentes de contaminação pelo $\mathrm{HCH}$ na amostra estudada.

Tabela 2. Concentrações sangüineas médias de $p-p ' D D E$ por local de residência, em crianças residentes no Municipio de Cubatão, SP.

\begin{tabular}{|c|c|c|c|c|c|c|c|c|c|}
\hline \multirow{2}{*}{$\frac{\text { Bairro }}{\text { Jd. C. Silva }}$} & \multirow{2}{*}{$\begin{array}{c}N \\
73\end{array}$} & \multirow{2}{*}{$\begin{array}{c}\begin{array}{c}\text { Teor } \\
=0\end{array} \\
33\end{array}$} & \multirow{2}{*}{$\begin{array}{c}\% \\
45,2\end{array}$} & \multicolumn{3}{|c|}{$\begin{array}{c}\text { Var. Individuais } \\
\mu \mathrm{g} / \mathrm{l}\end{array}$} & \multicolumn{3}{|c|}{$\begin{array}{c}\text { Média } \pm D P \\
\mu g / .\end{array}$} \\
\hline & & & & 0 & $<->$ & 15,5 & 1,16 & \pm & 2,33 \\
\hline V. Elizabeth & 61 & 15 & 24,6 & 0 & $<->$ & 6,9 & 0,71 & \pm & 1,63 \\
\hline V. Pescadores & 59 & 12 & 20,3 & 0 & $<->$ & 8,3 & 0,59 & \pm & 1,48 \\
\hline Pelicas & 9 & 3 & 33,3 & 0 & $<->$ & 4,0 & 0,98 & \pm & 1,60 \\
\hline C. Trilhos & 17 & 4 & 23,5 & 0 & $\langle\rightarrow$ & 2,1 & 0,42 & \pm & 0,80 \\
\hline C. Pilöes & 23 & 6 & 26,1 & 0 & $<->$ & 19,6 & 1,11 & \pm & 4,07 \\
\hline Total & 242 & 73 & 30,2 & 0 & $<->$ & 19,6 & 0,85 & \pm & 2,13 \\
\hline
\end{tabular}

Tabela 3. Concentraçōes sangüíneas médias de p-p'DDE por situaçāo de consumo, em crianças residentes no Município de Cubatăo, SP.

\begin{tabular}{|c|c|c|c|c|c|c|c|}
\hline \multirow{2}{*}{$\begin{array}{c}\begin{array}{c}\text { Situação } \\
\text { Consumo }\end{array} \\
+-\end{array}$} & \multirow{2}{*}{$\frac{N}{17}$} & \multicolumn{3}{|c|}{$\begin{array}{c}\text { Var. Individuais } \\
\mu \mathrm{g} / \text {. }\end{array}$} & \multicolumn{3}{|c|}{$\begin{array}{c}\text { Média } \pm D P \\
\mu g / .\end{array}$} \\
\hline & & 0 & $\langle->$ & 4,0 & 0,91 & \pm & 1,30 \\
\hline-- & 29 & 0 & $\langle\rightarrow>$ & 3,2 & 0,43 & \pm & 0,85 \\
\hline
\end{tabular}

+ - grande consumidor

- - não consumidor 
Tabela 4. Concentraçoses sangüineas médias de $\mathrm{HCH}$ total por sexo e faixa etária, em crianças residentes no Municipio de Cubatão, SP.

\begin{tabular}{|c|c|c|c|c|c|c|c|}
\hline \multirow{2}{*}{$\frac{\begin{array}{c}\text { Faixa } \\
\text { Etária }\end{array}}{1 \vdash 5}$ Fem. } & \multirow{2}{*}{$\frac{N}{47}$} & \multicolumn{3}{|c|}{$\begin{array}{c}\text { Var. Individuais } \\
\mu \mathrm{g} / \text {. }\end{array}$} & \multicolumn{3}{|c|}{$\begin{array}{c}\text { Média } \pm D P \\
\mu g / .\end{array}$} \\
\hline & & 0 & $<->$ & 3,8 & 0,24 & \pm & 0,76 \\
\hline Mase. & 45 & 0 & $\langle-\rangle$ & 3,3 & 0,21 & \pm & 0,64 \\
\hline $5 \vdash 11^{\text {Fem. }}$ & 81 & 0 & $\langle\rightarrow$ & 5,1 & 0,40 & \pm & 1,00 \\
\hline Masc. & 69 & 0 & $\langle->$ & 2,6 & 0,20 & \pm & 0,57 \\
\hline Total & 242 & 0 & $\langle\rightarrow\rangle$ & 5,1 & 0,28 & \pm & 0,79 \\
\hline
\end{tabular}

Tabela 5. Concentraçőes sangưineas médias de $\mathrm{HCH}$ total por situaçăo de consumo, em crianças residentes no Município de Cubatảo, SP.

\begin{tabular}{|c|c|c|c|c|c|c|c|}
\hline \multirow{2}{*}{$\begin{array}{c}\begin{array}{c}\text { Situação } \\
\text { Consumo }\end{array} \\
+-\end{array}$} & \multirow{2}{*}{$\frac{N}{17}$} & \multicolumn{3}{|c|}{$\begin{array}{c}\text { Var. Individuais } \\
\mu g / .\end{array}$} & \multicolumn{3}{|c|}{$\begin{array}{c}\text { Média } \pm D P \\
\mu g / .\end{array}$} \\
\hline & & 0 & $\langle\rightarrow>$ & 2,0 & 0,32 & \pm & 0,65 \\
\hline-- & 29 & 0 & $\langle->$ & 3,8 & 0,21 & \pm & 0,76 \\
\hline
\end{tabular}

Tabela 6. Plumbernia média por sexo e faixa etária em crianças residentes no Município de Cubatão, SP.

\begin{tabular}{|c|c|c|c|c|c|c|c|}
\hline \multirow{2}{*}{$\frac{\begin{array}{c}\text { Faixa } \\
\text { Etária }\end{array}}{1 \vdash 5^{\text {Fem. }}}$} & \multirow{2}{*}{$\frac{N}{39}$} & \multicolumn{3}{|c|}{$\begin{array}{l}\text { Var. Individuais } \\
\mu \mathrm{g} / \mathrm{dl} \text {. }\end{array}$} & \multicolumn{3}{|c|}{$\begin{array}{c}\text { Média } \pm D P \\
\mu g / d l .\end{array}$} \\
\hline & & 6 & $\langle->$ & 25 & 15,77 & \pm & 5,05 \\
\hline Masc. & 26 & 9 & $\langle->$ & 28 & 19,19 & \pm & 4,79 \\
\hline $5 \vdash 11^{\text {Fem. }}$ & 71 & 6 & $<\rightarrow$ & 34 & 18,39 & \pm & 5,92 \\
\hline Masc. & 61 & 4 & $\langle->$ & 31 & 17,84 & \pm & 6,32 \\
\hline Total & 197 & 4 & $\langle->$ & 34 & 17,81 & \pm & 5,82 \\
\hline
\end{tabular}

Na Tabela 5 -encontram-se as concentrações médias de $\mathrm{HCH}$ total no sangue por situação de consumo de peixes e/ou outros organismos dos rios de Cubatão. As taxas sangüíneas médias de $\mathrm{HCH}$ total não diferem estatisticamente, a um nível de significância igual a 5\%, entre consumidores e não-consumidores.

Das 251 crianças da amostra, foi possivel determinar a plumbemia em 197 delas (78,5\%). A Tabela 6 mostra os teores médios de chumbo no sangue por sexo e faixa etária. Não foi verificada diferença estatística, a um nível de significância igual a $5 \%$, entre teores medios de chumbo no sangue segundo sexo e faixa etária.

Considerou-se a plumbemia média de 17,81 ug/d1. como concentração elevada, tendo-se em conta a faixa etária pesquisada. Vahter ${ }^{28}$, em estudo realizado em 10 países, pesquisou a concentração mediana de chumbo no sangue entre professores, com estratificação para o tabagismo. A mediana de $17,63 \mu \mathrm{g} / \mathrm{dl}$. encontrada nas crianças de Cubatão só foi inferior a do México e a de fumantes belgas. Os presentes achados superaram os dos demais países.

Fine e col. ${ }^{12}$ verificaram em crianças norteamericanas plumbemias médias que variaram de 19,8 a $32,9 \mu \mathrm{g} / \mathrm{dl}$.

Cohen e col. ${ }^{3}$ pesquisando crianças residentes em zona urbana nos Estados Unidos da América do Norte (EUA) descreveram plumbemia média de $32,7 \pm 14,8 \mu \mathrm{g} / \mathrm{dl}$. 
Fernicola \& Azevedo ${ }^{13}$ encontraram, em 1981, em adultos residentes no Município de São Paulo, a plumbemia média de $12,4 \pm 4,8 \mathrm{ug} / \mathrm{dl}$.

Gelosa e col. ${ }^{14}$ verificaram que crianças italianas, residentes próximas a uma fundição de chumbo, apresentavam plumbemia média de $17,7 \pm 5,7$ ug/dl., bem semelhante ao teor médio encontrado nas crianças estudadas em Cubatão, não expostas ao metal.

Pesquisa realizada pela CETESB em $1983^{7}$, entre pré-escolares de Cubatão, apresentou plumbemias médias abaixo de $12,5 \mu \mathrm{g} / \mathrm{dl}$. em 9 das 10 escolas pesquisadas.

De acordo com Troster ${ }^{26}$, a Academia Nacional Norte-Americana de Ciências, em parecer de 1980 do Comitê de Chumbo no Meio Ambiente Humano, estabeleceu que plumbemias iguais a $10 \mu \mathrm{g} / \mathrm{dl}$. já podem determinar o aparecimento de alterações bioquímicas, com inibição de enzimas que entram na sintese da hemoglobina. Verificou-se que $92,9 \%$ das crianças estudadas em Cubatão apresentaram plumbemias iguais ou superiores a este limite.

A Environmental Protection Agency recomenda, nos EUA, que a plumbemia média em crianças não deveria exceder $15 \mu \mathrm{g} / \mathrm{dl}^{10}$. Todas as crianças que apresentaram plumbemia superior a este valor foram encaminhadas para acompanhamento ambulatorial. Por ocasião da primeira consulta, realizou-se a classificação do estado nutricional dessas crianças, utili- zando-se os critérios de classificação de Gomez ${ }^{15} \mathrm{e}$ Gomez e col. ${ }^{16}$ e os padróes do National Center of Health Statistics como referencia (OMS ${ }^{18}$ ). Das crianças encaminhadas, apenas uma delas apresentou desnutrição de primeiro grau, o que mostrou não ter havido interferência do estado nutricional nas concentraçōes sangüineas do chumbo.

Em função dos dados expostos, entende-se que é necessário desencadear estudos da toxicocinética do chumbo no ecossistema local e de monitoramento biológico, num estudo conjunto entre os órgãos de controle ambiental e de saúde pública.

A Tabela 7 mostra a concentração média de chumbo no sangue por situação de consumo de peixes e/ou outros organismos dos rios de $\mathrm{Cu}$ batão. Não se observou diferença estatística, a um nível de significância igual a 5\%, entre os teores médios encontrados.

Das 251 crianças que compuseram a amostra estudada, foi possível determinar os teores sangüíneos de mercúrio em 224 delas $(89,2 \%)$. A concentração média verificada foi de $9,08 \pm 6,44 \mu \mathrm{g} /$. (Tabela 8). Não se encontrou diferença estatística, a um nível de $5 \%$, entre as concentraçð̋es médias de mercúrio no sangue, segundo sexo e faixa etária.

Sherlock e col. ${ }^{22}$, pesquisando 942 habitantes do Reino Unido, encontraram teor médio de 8,8 \pm $6,1 \mu \mathrm{g} /$. de mercúrio no sangue, valor parecido ao encontrado em Cubatão.

Tabela 7. Concentração média de chumbo no sangue por situaçnao de consumo, em crianças residentes no Municipia de Cubatão, SP.

\begin{tabular}{|c|c|c|c|c|c|c|c|}
\hline \multirow{2}{*}{$\frac{\begin{array}{c}\text { Situaçăo } \\
\text { Consumo }\end{array}}{+-}$} & \multirow{2}{*}{$\frac{N}{14}$} & \multicolumn{3}{|c|}{$\begin{array}{l}\text { Var. Individuais } \\
\mu \mathrm{g} / \mathrm{dl} \text {. }\end{array}$} & \multicolumn{3}{|c|}{$\begin{array}{c}\text { Média tDP } \\
\mu g / d l .\end{array}$} \\
\hline & & 9 & $\longleftrightarrow \longrightarrow$ & 30 & 19,29 & \pm & 6,88 \\
\hline-- & 24 & 9 & $\longleftrightarrow \longrightarrow$ & 28 & 17,21 & \pm & 4,59 \\
\hline
\end{tabular}

+ - grande consumidor

- não consumidor

Tabela 8. Concentração média de mercúrio no sangue por sexo e faixa etária, em crianças residentes no Município de Cubatāo, SP.

\begin{tabular}{|c|c|c|c|c|c|c|c|}
\hline \multirow{2}{*}{$\frac{\begin{array}{c}\text { Faixa } \\
\text { Etária }\end{array}}{1-5^{\text {Fom. }}}$} & \multirow{2}{*}{$\frac{N}{43}$} & \multicolumn{3}{|c|}{$\begin{array}{c}\text { Var. Individuais } \\
\mu \mathrm{g} / .\end{array}$} & \multicolumn{3}{|c|}{$\begin{array}{c}\text { Média } \pm D P \\
\mu g / .\end{array}$} \\
\hline & & 0 & $\langle->$ & 22 & 8,79 & \pm & 5,99 \\
\hline Masc. & 34 & 1 & $\langle\rightarrow$ & 19 & 8,59 & \pm & 5,53 \\
\hline \multirow{2}{*}{$5 \vdash^{11}{ }_{\text {Mase. }}^{\text {Fen }}$} & 79 & 0 & $<\rightarrow$ & 31 & 8,86 & \pm & 6,00 \\
\hline & 68 & 1 & $\langle\rightarrow$ & 35 & 9,78 & \pm & 7,62 \\
\hline Total & 224 & 0 & $\longleftrightarrow \rightarrow$ & 35 & 9,08 & \pm & 6,44 \\
\hline
\end{tabular}


Tabela 9. Concentração média de mercúrio no sangue por situação de consumo, em crianças residentes no Municipio de Cubatāo, SP.

\begin{tabular}{|c|c|c|c|c|c|c|c|}
\hline \multirow{2}{*}{$\begin{array}{r}\begin{array}{r}\text { Situaçãa } \\
\text { Consumo }\end{array} \\
+-\end{array}$} & \multirow{2}{*}{$\frac{N}{17}$} & \multicolumn{3}{|c|}{$\begin{array}{c}\text { Var. Individuais } \\
\mu g / \text {. }\end{array}$} & \multicolumn{3}{|c|}{$\begin{array}{c}\text { Média } \pm D P \\
\mu \mathrm{g} / l .\end{array}$} \\
\hline & & 7 & $\langle\rightarrow$ & 35 & 14,65 & \pm & 7,05 \\
\hline-- & 27 & 2 & $\longleftrightarrow \longrightarrow$ & 22 & 10,00 & \pm & 6,52 \\
\hline
\end{tabular}

A Tabela 9 mostra a concentração média de mercúrio no sangue por situação de consumo. As crianças grandes consumidoras de peixes e/ou outros organismos dos rios de Cubatão apresentaram concentrações sangüíneas médias de mercúrio significativamente mais elevadas $(p<0,05)$ do que as crianças não-consumidoras.

Muitos estudos têm demonstrado haver uma relação direta e positiva entre o consumo de peixes e a concentração sanguínea de mercúrio. Os dados apresentados na Tabela 9 são coerentes com esses estudos.

Turner e col. ${ }^{27}$ examinando 190 habitantes das cidades de Mancora e Cancas no Peru, encontraram o teor médio de $82 \mu \mathrm{g} / 1$. de mercúrio no sangue e concentraçōes que variaram de 11 a 275 $\mu \mathrm{g} / \mathrm{l}$. As famílias pesquisadas nessas duas cidades, consumiam a média de $10 \mathrm{~kg}$ de peixe por semana. Em contrapartida, na cidade de Morropon, famílias que consumiam a média de $2 \mathrm{~kg}$ de peixe por semana, apresentaram teor médio de $9,9 \mu \mathrm{g} /$. de mercúrio no sangue e concentraçðes que variaram de 3,3 a $25,1 \mu \mathrm{g} / \mathrm{l}$.

Skerfving ${ }^{23}$ encontrou em 162 suecos consumidores de peixes contendo 0,3 a $7 \mathrm{mg} / \mathrm{kg}$ de mercúrio, concentrações deste metal em células sangüíneas que variaram de 8 a $390 \mu \mathrm{g} / \mathrm{kg}$. Em outro grupo de 20 suecos consumidores de peixes contendo cerca de $0,04 \mathrm{mg} / \mathrm{kg}$ de mercúrio, os teores deste metal em células sangüíneas variaram de 8 a $45 \mu \mathrm{g} / \mathrm{kg}$.

Birke e col. ${ }^{2}$ encontraram em 13 pessoas consumidoras de peixes com a frequiência igual ou inferior a uma vez por semana, o teor médio de 9,6 \pm $1,3 \mu \mathrm{g} / \mathrm{kg}$ de mercúrio em células sangüúneas. Em 5 indivíduos com ingestão moderada a alta de peixes contendo 0,5 a $6,7 \mathrm{mg} / \mathrm{kg}$ de metilmercúrio, o teor médio em células sangüíneas foi de $332,6 \mu \mathrm{g} / \mathrm{kg}$.

\section{Conclusóes}

De 242 determinações de pesticidas organoclorados realizadas, verificou-se a concentração mé- dia de p-p'DDE no sangue de $0,06 \pm 0,44 \mu \mathrm{g} /$. $O$ metabolito p-p'DDE foi encontrado em concentração média de $0,85 \pm 2,13 \mu \mathrm{g} /$. As crianças maiores de 5 anos apresentaram concentraçōes médias significativamente mais elevadas $(p<$ $0,05)$ comparadas às de menor faixa etária. A concentração sanguiínea média do isômero beta $\mathrm{HCH}$ foi de $0,22 \pm 0,63 \mu \mathrm{g} / \mathrm{l}$. $\mathrm{O}$ isômero gama $\mathrm{HCH}$ (Lindano) foi encontrado em 9 crianças e apresentou teores médios de $0,42 \pm 2,79 \mu \mathrm{g} / \mathrm{l}$. $\mathrm{O}$ isômero alfa $\mathrm{HCH}$ foi encontrado em concentração média de $0,01 \pm 0,1 \mu \mathrm{g} / \mathrm{l}$. Verificamos ainda duas crianças com teores detectáveis de $\mathrm{HCB}$ em sangue $(0,5$ e $0,8 \mu g / 1$.).

O teor médio de chumbo no sangue foi de 17,81 $\pm 5,82 \mu \mathrm{g} / \mathrm{dl}$., que foi considerado elevado para população infantil não exposta. Não foram encontradas diferenças significativas entre plumbemias médias por sexo e faixa etária. Não foi observada diferença significativa entre plumbemias médias de grandes consumidores de peixes e/ou outros organismos dos rios de Cubatão ( $\bar{x}=19,29 \pm 6,88 \mathrm{ug} / \mathrm{dl}$.) e de não consumidores de organismos aquáticos de qualquer origem $(\bar{x}=17,21 \pm 4,59 \mu \mathrm{g} / \mathrm{dl}$. $)$.

$O$ teor médio de mercúrio no sangue foi de $9,08 \pm 6,44 \mu \mathrm{g} /$. Não foram evidenciadas diferenças significativas entre os teores médios encontrados por sexo e faixa etária. Encontrou-se diferença estatística significante $(p<0,04)$ entre teores de mercúrio no sangue de crianças grandes consumidoras de produtos dos rios de Cubatão $(\overline{\mathbf{x}}=14,65 \pm 7,05 \mu \mathrm{g} / \mathrm{l}$.) e de crianças nãoconsumidoras de organismos aquáticos de qualquer origem $(\bar{x}=10,00 \pm 6,52 \mu \mathrm{g} /$. $)$.

\section{Agradecimentos}

À Gilmar da Cunha Trivelato, da FUNDACENTRO pela colaboração nas determinações de chumbo; à Rosângela Sartori Lui do Centro de Vigilância Sanitária da Secretaria de Estado da Saúde pela elaboração do mapa e outras inestimáveis colaboraçðes. 
SANTOS FILHO, E. et al. [Heavy metal and organochlorine pesticide blood levels in children aged between 1 and 10]. Rev. Saúde Pública, 27:59-67, 1993. A study of a sample of 251 children aged between 1 and 10 was carried out in 6 districts of Cubatão county, S. Paulo State, Brazil. This study showed the presence of organochlorine pesticides in the blood serum of 242 children. p-p' DDE was detected in 73 of the samples $(30 \%)$ and $\mathrm{HCH}$ in 47 them (19\%). The mean value of $\mathrm{p}^{\mathrm{p}} \mathrm{p}^{\prime} \mathrm{DDE}$ was $0.85 \pm 2.13 \mu \mathrm{g} /$. and that of $\mathrm{HCH}$ was $0.28 \pm 0.79 \mu \mathrm{g} / \mathrm{l}$. Lead and mercury were also detected in the blood serum. The mean value for lead was $17.8 \pm 5.8 \mu \mathrm{g} / \mathrm{l}$. and for mercury was $9.1 \pm 0.79 \mu \mathrm{g} / \mathrm{l}$. The levels found in consumers of aquatic organisms taken from the rivers of Cubatão showed a mean mercury level $(\bar{x}=14.7 \pm$ $7.1 \mu \mathrm{g} / \mathrm{l}$.) higher than $(p<0.04)$ that of those who did not consume any aquatic organisms at all $(\bar{x}=$ $10.0 \pm 6.5 \mu \mathrm{g} / \mathrm{l}$.).

Keywords: Organochlorine, blood. Lead, blood. Mercury, blood. Fishes.

\section{Referênclas Blbliográficas}

1. ALMEIDA, W. F. Níveis sangüíneos de DDT em individuos profissionalmente expostos e em pessoas sem exposição direta a este inseticida no Brasil. São Paulo, 1972. [Tese de Doutorado - Faculdade de Saúde Pública da USP].

2. BIRKE, G. et al. Studies on humans exposed to methylmercury through fish consumption. Arch. Environ. Health. 25: 77-91, 1972 .

3, COHEN, G. J. et al. Epidemiology of lead poisoning. JAMA., 226: 1430-3, 1973.

4. COMPANHIA DE TECNOLOGIA DE SANEAMENTO AMBIENTAL (CETESB). Relatório de qualidade das águas interiores do estado de Săo Paulo. São Paulo, 1989. (Série Relatónios).

5. COMPANHIA DE TECNOLOGIA DE SANEAMENTO AMBIENTAL (CETESB). Contaminantes na bacia do rio Cubatăo e seus reflexas na biota aquática. São Paulo, 1990.

6. COMPANHIA DE TECNOLOGIA DE SANEAMENTO AMBIENTAL (CETESB). Ação da CETESB em Cubatão: situação em janeiro de 1990. São Paulo, 1990.

7. COMPANHIIA DE TECNOLOGIA DE SANEAMENTO AMBIENTAL (CETESB). Avaliação toxicológica da exposição da população infantil de Cubatão a poluentes químicos do meio ambiente. São Paulo, 1984, v. 1.

8. COSTA, M. C. L. Correlação entre os níveis séricos de DDT e os títulos de anticorpos antidiftéricos circulantes em meninas pré-escolares de creches municipais na cidade de São Paulo, em 1975. São Paulo 1976. [Tese de Doutorado - Faculdade de Saúde Pública da USP].

9. DALE, W. E. \& MILES, J. W. Quantitative method for determination of DDT metabolites in blood serum. J. Ass. Off. Anal. Chem., 53: 1287-92, 1970.

10. DEVEAUX, P. et al. Blood lead levels in preschool children in Cape Town. SA Med.J., 69: 421-4, 1986.
11. FERNANDEZ, F. J. \& HILLGOSS, D. In improved graphite fumace methods for determination of lead in blood using matrix modification and the L'vov platform. Atom. Spectrosc., 3: 130-1, 1982.

12. FINE, P. R. et al. Pediatrics blood lead levels. A study in 14 Illinois cities of intermediate population. JAMA, 221: $1475-9,1972$.

13. FERNICOLA, N. A. G. G. \& AZEVEDO, F. A. Determinação dos níveis de chumbo associados à atividade enzimática do ácido gama-aminolevu línico desidratase e dos níveis de carboxi-hemoglobina no sangue de amostras populacionais do Estado de São Paulo. São Paulo, CETESB, 1983.

14. GELOSA, L. et al. Monitoraggio biológico di un campione di popolacione di etá scolares esposta ad inquinamento ambientale da piombo nel territorio limitrofo ad una fonderia. Ann. Ist. Super. Sanitá, 21: 29-36, 1985.

15. GOMEZ, F. Desnutrition. Bol. Med. Hosp. Infant. Mexico. 3: 543-51, 1946.

16. GOMEZ, F. et al. Mortality in second and third degree malnutriction. J. Trop. Pediat., 2: 77-83, 1956.

17. LARA, H. W. et al. Níveis de Dieldrin em sangue de aplicadores de Aldrin na região de São José do Rio Preto. São Paulo. Rev. Inst. Adolfo Lutz, 41: 9-14, 1981.

18. ORGANIZACION MUNDIAL DE LA SALUD. Medición del cambio del estado nutricional. Ginebra, 1983.

19. ORGANIZACIÓN PANAMERICANA DE LA SALUD. Criterios de salud ambiental: DDT y sus derivados. Washington, D. C., 1982. (Publ. cient., 425).

20. PERKIN-ELMER CORPORATION. Instructions mercury analysis system. Norwalk, Connecticut, 1971. p. 5-8.

21. RADOMSKI, J. L. et al. Blood levels of organochlorine pesticides in Argentina: occupationally and nonoccupationally exposed adults, children and newbom infants. Toxicol. Appl. Pharmacol., 20: 186-93, 1971.

22. SHERLOCK, J. C. et al. Duplication diet study on mercury intake by fish consummers in the United Kingdom. Arch. Envirom. Health. 37: 271-3, 1982.

23. SKERFVING, $S$. Methylmercury exposure, mercury levels in blood and hair, and health status in Swedes consuming contamined fish. Toxicology, 2: 3-23, 1974.

24. SUBRAMANIAN, K. F. \& MERANGER, J. C. A rapid eletrothermal atomic absorption spectometry methods for cadmium and lead in human whole blood. Clin. Chem., 27: 1866-71, 1971.

25. SUBRAMANIAN, K. F. Determination of lead in blood: comparison of two GFAAS methods. Atom. Spectrosc., 8: 7-11, 1987.

26. TROSTER, E. J. Exposição plúmbica em um grupo de gestantes e de recém-nascidos na grande São Paulo. São Paulo, 1986. [Dissertação de Mestrado - Faculdade de Saúde Pública da USP].

27. TURNER, M. D. et al. Methylmercury in populations eating large quantities of marine fish. Arch. Environ. Health, 35: 367-78, 1980.

28. VAHTER, M. ed. Assessment of human exposure to lead and cadmium through biological monitoring. In: Organización Panamericana de la Salud. Evaluación epidem. iologica de riesgos causados por agentes quimicos ambientales. Mexico, Noriega, 1988. p. 313.

Recebido para publicação em 5.3.1992 Reapresentado em 11.12.1992 Aprovado para publicação em 5.1.1993 